SHORT COMMUNICATION

\title{
Cytotoxicity and antioxidant activity studies of green leafy vegetables consumed in Sri Lanka
}

\author{
B. M. G. K. Balasuriya* and H. R. W. Dharmaratne \\ Natural Products Programme, Institute of Fundamental Studies, Hantana Road, Kandy.
}

\begin{abstract}
This investigation was conducted to examine the cytotoxicity and the antioxidant activity of some green leafy vegetables consumed in Sri Lanka. In this study, cytotoxicity was tested using brine shrimp (Artemia salina) lethality bioassay. As anticipated majority of the tested leafy vegetables were found to have insignificant cytotoxicity. However, some of the greens Aerva lanata and Baccopa monnieri showed significantly higher level of $(\mathrm{p}<0.001)$ cytotoxicity when compared with the positive control. Alternanthera sessilis which is the most popular leafy vegetable among Sri Lankans and Passiflora edulis showed similar toxicity levels as the positive control. Consumption of these four leafy vegetables could pose a potential health risk. Therefore, further toxicological studies should be carried out to evaluate their potential health risks. Antioxidant activity of above greens were tested using 2,2-diphenyl-1-picrylhydrazyl (DPPH) assay, and all the tested leafy vegetables showed free radical scavenging properties indicating the presence of primary antioxidants in the plants.
\end{abstract}

Key words: Antioxidant activity, Artemia salina, cytotoxicity, $\mathrm{DPPH}$, green leafy vegetables

\section{INTRODUCTION}

Green leafy vegetables (greens) play a significant role in the Sri Lankan diet probably due to the influence of traditional herbal medicine, their low cost and easy availability. Further, greens are a major source of vitamins, minerals and fiber. Due to scientific or other reasons, the use of certain herbs in the diet has been discontinued while others have been added. Information as well as misinformation plays a major role in this process. The removal of nutritional herbs from the diet based on inadequate or erroneous information denies access to an easily available cheap source of nutrients while use of herbs about which little is known may endanger human health. There are reports worldwide about misidentification of greens and culinary herbs, leading to the consumption of toxic herbs which can cause irreparable damage to organs and body function. Hence, there is a vital need to educate the general public on their choice of green leafy vegetables for consumption, which necessitates a systematic scientific evaluation of their nutritional properties as well as the toxic effects.

Antioxidants exert a protective role in cancer and tumor prevention processes in the human body by quenching oxidation type free radicals in blood. Therefore, it is essential to consume foods rich in antioxidants. The present investigation was focused mainly on cytotoxicity and antioxidant activity studies of popular greens and culinary herbs used in Sri Lanka.

\section{METHODS AND MATERIALS}

Thirty types of pesticide free green leafy vegetables were collected mainly from the field. Cleaned plant material $(100 \mathrm{~g})$ was macerated in distilled water $(100 \mathrm{~mL})$, filtered through a muslin cloth and filtrate was freezedried to get the water extract.

Brine shrimp (Artemia salina) lethality bioassay ${ }^{1,2}$ was used for the preliminary screening for cytotoxicity of water extracts of the leafy vegetables, as this assay has shown a good correlation with cytotoxicity assays with human cell lines and mouse bioassays ${ }^{1}$. Brine shrimp, Artemia salina eggs (imported from Pets Food, Sam Yu Foods Co.Ltd, Taiwan) were purchased from the local pet shop. Eggs were hatched in artificial sea water ${ }^{2}$ at room temperature $\left(27^{\circ} \mathrm{C}\right)$ and aerated for $48 \mathrm{~h}$. Second instar nauplii were used in the test since they have been reported to show the highest sensitivity ${ }^{3}$ to test substance.

\footnotetext{
${ }^{*}$ Corresponding author
} 
Tests were performed in the wells of 96-well plates in triplicates of 1000, 500, 100 and 10 ppm concentrations of the 30 freeze-dried water extracts of selected greens. Dimethyl sulfoxide (DMSO): seawater, 1:19 was used as the solvent. When the extract is water soluble, seawater was used as the solvent. DMSO: seawater ratio was determined by a separate experiment performed to detect the ineffective DMSO dilution. Ten $2^{\text {nd }}$ instar nauplii were added to each well of 96-well plates and the number of survivors was counted after $24 \mathrm{~h}$ of incubation at room temperature $\left(27^{\circ} \mathrm{C}\right)$. Quinoline in the solvent was used as the positive control, while negative control was performed by adding only the solvent. The test was repeated three times. $\mathrm{LC}_{50}$ values were calculated using
EPA probit analyzer version 1.5. The data were shown as mean \pm SE. One-way ANOVA with Fisher's comparison was adopted to evaluate the statistical significance. Probability level was fixed to $\mathrm{p}<0.05$ (Table 1 ).

2,2-diphenyl-1-picrylhydrazyl (DPPH) free radical scavenging assay was used for the preliminary screening of anti-oxidant activity ${ }^{4}$. Freeze-dried water extracts of green leafy vegetables and tocopherol (positive control) were spotted on thin layer chromatography (TLC) plates, and exposed to a free radical reagent $0.4 \mathrm{M}$ ethanolic solution of DPPH to visualize anti-oxidant activity. Antioxidants neutralize the purple colour DPPH free radicals in to bright yellow colour.

Table 1: Cytotoxicity of different vegetable greens on brine shrimps

\begin{tabular}{|c|c|c|}
\hline Botanical name & Vernicular name & $\mathrm{LC}_{50}$ value $(\mathrm{ppm})$ \\
\hline Alternanthera sessilis & Mukunuwanna & $185.31 \pm 0.01^{\Delta}$ \\
\hline Centella asiatica & Gotukola & $793.33 \pm 1.81$ \\
\hline Murraya koenigii & Karapincha & $810.45 \pm 8.37$ \\
\hline Brassica sativa & Kola goa & $308.80 \pm 13.1$ \\
\hline Ipomoea aquatica & Kankun & $385.02 \pm 1.21$ \\
\hline Basella alba & Nivithi kola & $>1000$ \\
\hline Passiflora edulis & Passion Kola & $176.48 \pm 0.25^{\Delta}$ \\
\hline Dregea volubilis & Aguna Kola & $250.47 \pm 0.27$ \\
\hline Solanum indicum & Tibbatu & $519.38 \pm 5.87$ \\
\hline Solanum nigrum & Kalukamberiya & $268.47 \pm 8.82$ \\
\hline Vernonia cinera & Monarakudumbiya & $>1000$ \\
\hline Acalypha indica & Kuppameniya & $267.86 \pm 8.65$ \\
\hline Asparagus officinalis & Hathawariya kola & $253.27 \pm 9.82$ \\
\hline Costus speciosus & Tebu kola & $>1000$ \\
\hline Sesbania grandiflora & Kathurumurunga & $519.38 \pm 5.87$ \\
\hline Sapindus halicacabum & Pennla & $393.71 \pm 4.63$ \\
\hline Amaranthus viridis & Kura & $591.38 \pm 2.39$ \\
\hline Lasia spinosa & Kohila dalu & $738.08 \pm 8.02$ \\
\hline Carum petroselinum & Parsley leaves & $>1000$ \\
\hline Coccinia grandis & Kowakka kola & $>1000$ \\
\hline Colocasia esculenta & Kalualakola & $358.99 \pm 0.05$ \\
\hline Polyscias scutellaria & Koppa kola & $210.80 \pm 0.17$ \\
\hline Lactuca sativa & Salada & $292.71 \pm 3.02$ \\
\hline Sauropus androgynus & Japanbatu kola & $291.25 \pm 2.33$ \\
\hline Coriandrum sativum & Koththamalli kola & $440.95 \pm 5.32$ \\
\hline Cassia auriculata & Ranawara & $513.75 \pm 5.06$ \\
\hline Mentha viridis & Minchi & $387.18 \pm 2.96$ \\
\hline Aerva lanata & Polpala & $77.95 \pm 0.62 * *$ \\
\hline Baccopa monnieri & Lunuwila & $34.84 \pm 0.13 * *$ \\
\hline Positive control & Quinoline & $159.77 \pm 1.45$ \\
\hline
\end{tabular}

Values are mean \pm standard error $(n=3)$, One-way ANOVA with Fisher's comparison. Other than ${ }^{\Delta}$-values all the values are significantly different $(\mathrm{p}<0.001)$ than the positive control. $* *$ - values are significantly lower than the positive control. ${ }^{\Delta}$ - values are not significantly different than the positive control. 


\section{RESULTS}

It is observed that, most of the tested plant extracts such as Centella asiatica, Ipomoea aquatica, Sesbania grandiflora, Murraya koenigii, Basella alba, Cardiospermum halicacabum, Vernonia cinerea, Costus speciosus, Lasiaspinosa,Coriandrumsativam, Menthaviridis, Carum petroselinum, Amaranthus viridus and several others (see table 1 ) have significantly higher $(\mathrm{p}<0.001) \mathrm{LC}_{50}$ than the positive control. $\mathrm{LC}_{50}$ of the water extracts of Aerva lanata and Baccopa monnieri were found to be significantly lower $(\mathrm{p}<0.001)$ than the positive control. Water extracts of Alternanthera sessilis and Passiflora edulis showed $\mathrm{LC}_{50}$ values, which are not significantly different from the positive control.

Interestingly all the extracts and the positive control tocopherol gave yellow spots, showing neutralization of the dark purple free radical, indicating the presence of free radical scavenging compounds in the plant extracts.

\section{DISCUSSION}

When $\mathrm{LC}_{50}$ values of all the leafy vegetables were analyzed using one-way ANOVA and Fisher's comparison with the positive control, other than A. sessilis, P. edulis, A. lanata and B. monnieri rest of the extracts were found to be significantly $(\mathrm{p}<0.001)$ higher than the positive control (Quinoline), indicating their non cytotoxicity. It is observed that the $\mathrm{LC}_{50}$ values of $A$. lanata and B. monnieri are significantly lower than the positive control, indicating their higher cytotoxicity. Further, it is noted that according to the $\mathrm{LC}_{50}$ values, $A$. sessilis and $P$. edulis are equally toxic as the positive control to the Brine shrimps. Therefore, despite the fact that the majority of the extracts which have shown significantly higher $\mathrm{LC}_{50}$ values are non toxic, one can argue that consumption of $A$. sessilis, $P$. edulis, $A$. lanata and $B$. monnieri could lead to potential health risks.

According to the house-hold income and expenditure survey of Sri Lanka (2004) A. sessilis, locally known as Mukunuwenna / Ponankani, is consumed widely among Sri Lankans. That is mainly because of its taste and comparatively low costs; and large quantities are often being consumed in a single meal. Therefore, there is an important need for more investigations on toxicological aspects to evaluate their potential health risks to human beings. As the literature on toxicological studies of A. sessilis is inadequate, further toxicity studies should be carried out using cell lines and in vivo models to investigate their potential health risks. However, Broccoli
(Brassica oleracea var. italica), a very popular vegetable in the Western world is also claimed to be cytotoxic ${ }^{5}$. Yet no health warnings to the general public have been imposed by the respective authorities of these countries regarding eating Broccoli. Accordingly, consumption of fair amounts of $A$. sessilis may not posses health risks to human. Toxicity of $A$. lanata ${ }^{6}, B$. monnieri ${ }^{7}$ and $P$. edulis ${ }^{8}$ are previously reported, and our results are comparable with the literature data. However, in Sri Lanka A. lanata and B. monnieri are not consumed widely as leafy vegetables although used in traditional medicine.

Free radical scavenging properties demonstrate the presence of primary antioxidants in the plant extracts, which are claimed to be responsible for the chain braking and free radical scavenging in body tissues ${ }^{4}$. The above observed antioxidant activity of the water extracts of common vegetable greens consumed in Sri Lanka, is a clear positive indication of the selection of appropriate green leafy vegetables by the local population.

\section{Acknowledgement}

The authors thank Dr G. Senaviratne for his valuable advice on statistical analysis and Ms. R. S. M. Perera and Mr. D. S. Jayaweera for technical assistance.

\section{References}

1. Lee T-H., Chen Y-M. \& Chou H-N. (1999). Toxicity of cyanobacterial strains using Artemia salina in comparison with the mouse bioassay. Acta Zoologica Taiwanica 10(1): $1-8$.

2. Michael A.S., Thompson C.G. \& Abramovitz M. (1956). Artemia salina as a test organism for bioassay. Science 123: 464.

3. Carball J.L., Hernandez-Indal Z.L., Perezl P. \& GarciaGravalos M.D. (2002). A comparison between two brine shrimp assays to detect in vitro cytotoxicity of marine natural products. BMCBiotechnology 2: 17-28.

4. Mattei R. (1998). Guarana (Paullina cupana): toxic behavioral effects in laboratory animals and antioxidants activity in vitro. Journal of Ethnopharmacology 60(2): 111-116.

5. Martinez A., Ikken Y., Cambero M.I., Marin M.L., Haza A.I., Casas C. \& Morales P. (1999). Mutagenicity and cytotoxicity of fruits and vegetables evaluated by the Ames test and 3-(4,5-dimethylthiazol-2-yl)2,5-diphenyltetrazolium bromide (MTT) assay. Food Science and Technology International 5 (5): 431-437.

6. Chowdhury D., Sayeed A., Islam A., Shah Alam Bhuiyan M. \& Astaq Mohal Khan G.R.M. (2002). Antimicrobial activity and cytotoxicity of Aerva lanata. Fitoterapia 73: 92-94. 
7. D'Souza P., Deepak M., Rani P., Kadamboor S., Mathew A., Chandrashekar A.P. \& Agarwal A. (2002). Brine shrimp lethality assay of Bacopa monnieri. Phytotherapy Research 16(2):197-198.
8. Spencer K.C. \& Seigler D.S. (1983). Cyanogenesis of Passiflora edulis. Journal of Agricultural and Food Chemistry 31:794-796. 